\title{
How Perception-Based Decisions Can Negatively Shape Your Leadership Performance (Decision-Making and Behavior)
}

\author{
Vincent Jemison Ph.D.* \\ Department of Management in Organizational Leadership, University of Phoenix, Arizona \\ Email: drewjemi@email.phoenix.edu
}

\begin{abstract}
Keywords: Politics Leadership, Dangerous Behavior, Decision-making, Perception, Arousal, Mental Health
\end{abstract}

\begin{abstract}
In present-day, one of the most subtle means political leaders use to influence their base of supporters is through verbal communication. Over the past two years, some political leaders have increasingly relied on "transferring their perception onto their base of followers, which often negatively stimulates, arouses and shapes an individual's performance" (decision-making and behavior). In addition, to the detriment of our society, when political leaders transfer their perception onto their base of followers, they often misjudge the sensitive consequences of the prospective outcome. Here for the first time, research now shows that a displaced thought process is attributed to the underlying stimulation used to arouse the transfer of one's perception onto others. Therefore, because the dangerous cruel and often violent behavior that follows the transfer of one's perception has become so prevalent in our society, such performance warrants immediate exploration.
\end{abstract}

\section{Introduction}

Since 2018, the acceleration of political rhetoric suggests that many political leaders have come to rely on the transfer of their perception to justify their personal beliefs and concept formations when rendering a decision (Jackson, 2011; Crane, 2009; Braund, 2008). Here, for the first time, we report how "Negative arousing stimuli are remembered more often..." (Sharot, Delgado, \& Phelps, 2004) especially when delivered in the form of a displaced thought process (agitation, toleration, resonation, acceleration, or integration) (Lee, Donnelly, Cohen, et al., 2016). As a result, such displaced thought process stimulus is now known to arouse the transfer of subjective perceptions, which is considered to cognitively influence, and negatively shape an individual's performance (decision-making and behavior). According to Ochsner (2000) when it comes to negative stimuli, "There is a reason to hypothesize that different cognitive neural networks can be measured." The objective here is to identify and capture which displaced thought process is being transferred in the communicated rhetoric before it resonated, produces agitation, tolerance and is cognitively integrated and accelerated and later reciprocated into the individual's performance (decision-making and behavior) and actions.

Therefore, it is now critically essential to know that it is possible to measure the intensity of an individual's perception, because research now reveals how perception-based decisions follow a predictable path: The path leads to cruel verbal, mental, and or physical harm. For instance, when President Trump made the comments about what the national football league should do to players (Colin Kaepernick) who kneel during the national anthem, his most recent comments on Congresswoman Omar (Hayes, 2019; Stubley, 2019; AFP, 2019), Jussie Smollett and many, many others (Hoffman, Mather \& Fortin, 2017; Wright, 2017). This means now more than ever, political leaders can now be held accountable for how they communicate the transfer of their perception-based decisions (Brewer, 2012; Yukl \& Mahsud, 2010; Frederiksen, 2010) onto their base of followers. Some leading researchers now consider this way of communication as "Dangerous behavior" (Lee, Donnelly, Cohen, et al., 2016). According to Talarico (2003), "The subjective sense of subconscious remembering when influenced by 'agitation' for instance is often taken into account as an actual accurate experience." When it comes to the cognitive process of transferring one's perception, "It is 
the perception others hold about an individual's power that gives that person the ability to achieve influence over another person" (Jemison, 2018).

This paper describes how this pattern of arousal is related to the heightened subjective subconscious experiences that are influenced by a displaced thought process. Furthermore, to provide readers with a clear path of the intent of this paper, conclusions were drawn from the celebrated observational study by Paul Little, Hazel Everitt, and Ian Williamson (2001), which focused on "Measuring targeted communication that followed decisions made by patients concerning the perceptions of their recovery." The results of Little et al's (2001) work revealed how an individual's perceived decisions about their own recovery were often influenced by psychosomatic beliefs and concept formations of their past experiences (Kassam, Koslov \& Mendes 2009; Bandura, 2001). The findings of Little et al. research validated this paper by establishing "The necessity of optimizing individual leadership performance" in order to properly measure the intensity of perception-based decisions that followed a predictable path (Bacon, 2007; Kets de Vries \& Korotov, 2007; Daudelin, 1996) as this paper suggests.

\section{Theory}

According to Jemison (2018), "Perception is defined as the "Necessary existence of displaced energy influenced by time action and belief." It is further noted that, the reason why perceptionbased decisions are believed to be necessary, is that the individual exercising such decision-making and behavior feels so strong about a similar past experience that their present decision is the only way to solve the problem. This stimulus is aroused by a displaced thought process that suggest what has made the person feel that, that decision was "necessary" and only was necessary because of another person's resistance to their reasoning. It is here that, studies examining memories of arousing reallife events show that arousal is heightened from strong feelings of past experiences: Without necessarily enhancing the objective accuracy of the past experience to the current situation at hand. It is strongly suggested that because "Concept formations form judgments, is the reason why some political leaders (individuals) have come to rely on their past experiences to arouse the transfer their perception-based decisions onto others, which this paper suggests negatively shapes an individual's leadership performance (decision-making and behavior)." With this in mind, for the first time, research victories have been made revealing that it is possible to "Measure the intensity of perceptionbased decisions" because such decisions follow a predictable path.

\section{Literature Review}

It is appropriate to begin this section with literature that describes Albert Bandura's (2001) "Social Cognitive theory," to understand why it is important to a measure individual's leadership performance. Bandura's social cognitive theory underlines how internal and external subconscious experiences can be used to measure the intensity of an individual's perception-based decisions (Crothers, Hughes, \& Morine 2008). Bandura believed that the origin of an individual's subconscious reasoning takes place when in an environment where observations, decisions, and behaviors have been adapted and processed through social and institutional learning (Northouse, 2010). For instance, the thought process that develops an individual's internal perceived self-worth because of their wealth, race, gender, or financial and family status.

With this in mind, Doris Collins in 2002 performed a study that obtained outcomes of eighty-three studies on "Performance-level evaluation methods in management..." that supports innovative methods for measuring an individual's leadership performance (decision-making and behavior).

Collins work came after collaborating her theories with the inspiring work of (Newstrom, 1995) which identified significant gaps in (Ellis \& Davidi, 2005) cognitive neuro-feedback models that could be later applied to research targeting the optimization of an individual's leadership performance. Collins theories also suggested that the performance management interventions identified in her work produced the means of applying (Kassam, Koslov \& Mendes 2009) neurobiofeedback related to how individuals transfer subconscious subjective perceptive beliefs onto others 
when personally engaged. Overall, the finding of Collins study supports the argument of this article, which specially focuses on an innovative approach that identifies the "psychosomatic" significance for measuring the intense transfer of communicated perception. According to some researchers, today it is critically important to evaluate our political leader's psychosomatic performance, especially performance that affects all members of our society, especially women and other marginalized groups.

\section{Theorizing the Implicit Content of Perception-Based Decisions}

In this paper, I shared from the findings of my research how the state of applied performance could reveal real-time neurofeedback for measuring the intensity of individual perception-based decisions that follow a predictable path. To measure a real-time perception-based decision, individual leadership performance is conceptualized through the optimization of an individuals reasoning capability. In theory, a real-time measurement is based on the level of influence of a displaced thought process (energy model) as the individual cognitively processes information about their environment, based on past experiences, especially when engaged in situations of uncertainty. The overarching objective of theorizing the implicit content of perception-based decisions is measuring how the transfer of perception has influenced an individual's performance (decision-making and behavior). As a result, this behavior can now be measured based on the attributes of dangerous behavior that are often carried out in the form of cruel mental, verbal, and even physical harm.

\section{The Significance and Necessity of Measuring Perception-Based Decisions}

Measuring the intensity of perception remains a neglected issue of research on "perception". The theories needed to ensure researcher are able to properly measure the intensity of an individual's perception is all around us, but just hidden from our sight because we are often blinded by someone else's personal biases or ours. The very notion of measuring the intensity of perception has long been shown to be subtle, elusive, and was never precisely matched to the physiological arousal of negative stimuli of a person's past experiences, which for example has now become a common practice of President Trump's leadership performance. This paper also presents an argument in favor of reframing all perception-based decisions into a psychosomatic field of study. The objective here would be to identify how perceptive concept formations and chronological oppressive factors influence an individual's leadership performance (decision-making and behavior) over time, in order to properly investigate the significance and necessity for measuring the intensity of an individual's perception.

LeMay, Vollmer, and Ellis (2007) noted that, in the present day, "It is appropriate that political leaders have their individual leadership performance measured." LeMay, Vollmer, and Ellis's argument suggested that "To expect changes in the discursive communication, prominent political leaders must be held responsible for the transfer of all of their perception-based performance." For example, measuring the dangerous behavior influenced by a political leader's perception-based decision that provides a directive to enforce or change a constitutional law or a judicial or executive policy. Current research suggests that the transfer of communicated perception has now become an obvious practice of many federal and state lawmakers, including police officers, especially in their reasoning for allocating resources, and enforcing laws they were hired to enforce (Hannum, Martineau, \& Reinelt, 2007; Goleman, 2000; Heifetz \& Laurie, 1997).

\section{The Moral Challenges of Perception-Based Performance}

Over the past two years, a common question that prevents most political leaders from taking a stand regarding issues of right and wrong is the question concerning the moral challenges in perception-based performance. The 2009 work of Steve Guglielmo, Andrew Monroe, and Bertram Malle titled "At the Heart of Morality Lies Folk Psychology" was relied upon to add value to this paper. The findings of Guglielmo et al's (2009) work, showed how the influences of folk psychology are formed within an individuals internalized thoughts as either intentional, a choice, or free will when transferred onto others. The significance of Guglielmo et al.'s work suggested that choice is the 
main reason that defines the psychosomatic behavior of passing judgment and perpetuating the negative transfer of communicated perceptions onto others.

In support of Guglielmo et al's (2009) work, Yamashiro (2013) noted that political leaders should be examined often to determine how the intensity to which their personal subconscious biases negatively influences theirs and the actions of others. According to Yamashiro (2013), "When an individual makes a judgment based on the perception of another person, that judgment is internalized based on an individual's 'Working memory;' which has been known to trigger "Dangerous behavior" (Lee et al, 2016). For example, when an individual makes a judgment of another person's social status, or position of power, at this point, based on such "Working memory" the performance can now be measured based on the intensity of the displaced thought process that triggered the judgment. It is here that any form of investigation into measuring the intensity level of perception to determine which displaced thought process stimulated an individual's performance before, while, and even after transferring one's perception onto another person begins.

In general, Guglielmo et al.'s work support Albert Bandura's theory, which also revealed that the inner workings of an individual's cultural values and personal intent are the core components for identifying the cognitive practice immoral judgment of blaming, and assigning blame onto those who oppose them. The question then becomes, what is the "Intensity" level of the energy model (displaced thought process) that stimulated the individual's performance. With this in mind, the previous work of Anda, Feliti, and Bremner (2006) has confirmed that "Evidence of the exacerbation of blaming and assigning blame on those who oppose a person's intent has been observed in their research on Adverse Childhood Experiences (ACE)". Anda et al.'s study, concluded that "cruel mental, verbal and physical harm are major risk factors for further violence...;" especially when someone has and is transferring their perception onto their followers for instance.

\section{The Negative Morality of Perception}

In consideration for Cushman, Young, and Hauser's work titled, "The Role of Conscious Reasoning, and Intuition in Moral Judgment," the definition of morality derived from their work suggested that some individuals in high political leadership often blur the boundaries between perception and structured leadership when it comes to the way they communicate to their base. In 2006, Keith Ansell-Pearson and Carol Diethe translated Friedrich Nietzsche's study, on "The Genealogy of Morality," and arrived at the conclusion that "He who has the power to avenge, good with good, and evil with evil, actually practices and believe they are an avenger; and to their base are considered grateful and revengeful, and is perceived as good."

Ansell-Pearson and Diethe further translated Nietzsche as suggesting, the issue is not only he who does harm is bad, but also, he who is contemptible is counted as bad. The translations of AnsellPearson and Diethe also suggested that because of this historical view, some male political leaders essentially have forgotten to be moral and to be ethical. In other words, some political leaders have come to rely on the practice of transferring their perceptions through negative rhetorical discourse to inspire their base.

For example, according to Sonmez, (2019), "House Speaker, Nancy Pelosi had to demand extra security to protect Congresswoman Omar, because President Trump intently transferred his perception to his base, resulting in reciprocated behavior reflected in increased death threats made on her life." Keith Ansell-Pearson and Carol Diethe translations on "The Genealogy of Morality" were a credit to the focus of this article because their conclusions identified specifically how an individual's immoral performance (decision-making and behavior) can be stimulated through an intentional transfer of perception. As we see play out, in the above example where perceptions are deliberately being communicated onto others, the results are often reciprocated in the form of dangerous behavior that followed cruel mental, verbal, and even physical violent harm unto others.

\section{Deconstructing the Transfer of perception}

Although internalized explanations of the deliberate transfer of communicated perception have become more evident, deconstructing the narratives of such transfer is now very necessary and warrants immediate exploration (Derrida, 2004) ergo the creating of this paper, which if left 
unchecked will lead to an anomaly, which is inherent in every human being. The process of deconstructing the captured narratives of communicated perceptions is achieved by pinning down which displaced thought process is most signified in the narrative in order to identify subconscious learning that stimulated the intent of a conscious transfer of perception (Tosey, Visser, \& Saunders, 2012). The most intriguing question presented in this paper is, are you ready to accept how the cognitive challenges perception has negatively influenced every person in this world. Today subconscious learning that stimulates the intent of a conscious level of transfer of perception has infiltrated into the functional and transactional foundations of our social institutions, including educational and other public organizations (Weigel, 2008). With this in mind, deconstructing the captured narratives of an individual's perception-based decision is based on establishing the window of opportunity for "Optimizing an individual's leadership performance" (Vogel, Wade, and Hackler, 2007; Derrida, 2004; Friston, Daunizeau, and Kiebel's, 2009). Leakman, Panter-Brick, and Saleh (2014) argued that "Childhood experiences of conflict, physical and emotional neglect can lead to developmental psychosomatic of damaging thought patterns that can play out into future dangerous behavior in the form of verbal, mental, and even physical violence ...".

With this in mind, Veltman and Piper (2014) suggested that conflict and oppression should be taken into account when evaluating a person's psychosomatic behavior, which can be overt or conducted secretly without the oppressed person(s) knowing they are being oppressed.

Herek, Gillis, and Cogan (2009) argued that oppression is commonly formed in the context of internalized perceptions, which can be "observed in cases where an individual or group believes that those who oppose them do not conform" to the internal expectations and controls of a dominant group. Veltman and Piper (2014) supported the views of Herek et al., by highlighting how oppression is internally manifested in different ways when stimulated by a displaced thought process. According to Postmes and Smith (2009), a good example of individual's practicing control over others is when mainstream members of society support obvious and blatant influences of discrimination and approve the action(s) and behavior it represents. For example, failure to punish race-related hate speech or support for sexist speech, or smearing reputable individuals of our society (Schneider \& Bos 2014; Killen, Rutland, \& Jampol, 2008).

\section{Results}

In this article, I relied upon my research study that focused on how negative influences of "Perception" shapes an individual's leadership performance. The discussions presented in my study concluded, that the transfer of communicated perception is often based on a subconscious experience that when consciously called upon is often stimulated by a displaced thought process and based on a selective and assumed past experience (Wang, 2007; Hartley \& Tranfield, 2011). During my study, all of the participant's echoed sentiments that the transfer of communicated perception indeed encompasses personal oppressive influences from past experiences, which some considered as a way of life (Burke, 2013).

To properly interpret Burke's above citation, Michel Foucault's 1980 work on "Power and Knowledge" was referred upon. Foucault's work supported how most present-day political leader's performance (decision-making and behavior) is heavily influenced by their perceptions (Chiu, Gelfand, Yamagishi, Shteynberg \& Wan, 2010). Even when organizational policy and laws are in place for individuals to adhere to, individual perception(s) still subconsciously influences the performance of some political leaders (Kirkpatrick \& Kirkpatrick, 2005). Over half of the participants in my study voiced that "From a governance and policy-making point of view, the ability to stop relying on their perception-based decisions would be welcomed" (Elmuti, Jai, \& Davis, 2009).

\section{Discussion}

Again, the reason this article is so important because it allows researchers to ask the question of, "Why are political leaders intently transferring their perception unto their base?" In consideration of the theories presented in this paper, if political leaders who are intent on "Transferring their 
perceptions" onto their base, this behavior exhibits the practice of dangerous behavior. Overall, such behavior will attribute to long-term mental health and social conflicts on the fabric of American life, its people, our American values and threaten the world's view of the governing capacity of the United States of America's political leadership. Overall, there is growing concern from researchers that there is an urgent need for immediate exploration into the long-term effects in "How perception-based decisions negatively shape an individual's leadership performance (decision-making and behavior)."

\section{Conclusion}

The urgent importance for researching "How perception negatively shapes an individual's performance" especially those of political leaders, is because today, the intentional transfer of communicated perceptions are being reciprocated in our society in the form of the most cruel, dangerous behavior. For example, in the form of verbal, mental, and physical harm onto women and other marginalized groups. The question becomes, does measuring the intensity of perception-based decisions that follow a predictable path contribute to improving social change, and accountability of a political leader's performance? Throughout this paper, I discussed how an energy model (displaced thought process) often stimulates the transfer of perception-based decisions and the purpose of obtaining biofeedback from this transfer in order to measure the intense cruel verbal, mental, and physical harm of reciprocated performance from this transfer.

This reciprocated behavior is all around us and is not hidden from our sight any longer. As a result, "it has become critically important to identify impulsive reactions to all situations. I believe that in today's society "A more formal structured leadership approach is the only option to keep a record of how any threshold decision was made, what past experience it was based on, and who was involved." Measuring the intensity of a perception-based decision "might not be able to change an individual's performance, but it will help to recognize the value of applying the principles of structured leadership directed at optimizing an individual's future performance."

The nature of structured leadership and decision-making does differ considerably compared to a perception-based decision. In contrast, unlike structured-based decisions, perception-based decisions have "no one correct approach to personal governance." The circumstances surrounding perception-based decisions can vary considerably, and for the first time can be measured because such decisions follow a predictable path." If this is the case, "What happens when people do not trust each other?" Is it possible that "They will ignore, disguise, and distort facts; ideas, conclusions, and feelings that they believe will increase their perception of others?" All in all, the additional focus of this article suggests that everyone is a "Leader", simply because all leaders make decisions. For example, if an individual chooses to follow someone, a "decision" was made to do so.

Overall, "Many factors can influence and stimulate an individual's decision-making process". For instance, "prejudice or wishful thinking might affect someone's judgment." In addition, "Reliance is often placed on past experiences without consideration of past mistakes." It is here that, when "Making a decision using perception alone should not be an option, but is often merely done because it is the easy way out." Overall, because of the alarming increase in intense political discursive rhetoric that has endorsed and encouraged dangerous and violent behavior and actions against Asian Americans and other marginalized groups to promote a specific political agenda now justifies investigation. This paper was written to start a discussion that deliberately focuses on explaining how "Perception-based decisions follow a predictable path in the form of actionable dangerous cruel and often violent behavior." Therefore, it is very critical to note that because research now shows how perception-based decisions often follow a predictable path, measuring the intensity of such decisions especially when evaluating an individual's performance (decision-making and behavior) warrants further exploration.

\section{Conflict of Interest}

The author declare that there is no conflict of interest. 


\section{References}

[1] Anda, R.F., Felitti, V.J., and Bremner, J.D. et al. (2006). The enduring effects of abuse and related adverse experiences in childhood. A convergence of evidence from neurobiology and epidemiology. European Archives of Psychiatry and Clinical Neuroscience, 256(3):174-186.

[2] Anda, R.F., Chapman, D.F., Dong, M., Dube, S.R., Edwards, V.and Felitti, V.J. (2005). The wide-ranging health consequences of adverse childhood experiences. Victimization of children and youth: Patterns of abuse, response strategies. New Jersey: Civic Research Institute, https://acestoohigh.com/research/, accessed 27 May 2016.

[3] Bacon, H. (2007). Learning from experience. Clinical Child Psychology and Psychiatry, 12 (3), 369-373.

[4] Bandura, A. (2001). Social cognitive theory: An agentive perspective. Annual Review of Psychology, 52, 126.

[5] Braund, M. J., (2008) The structures of perception: An ecological perspective. Kritike, 2: 123144.

[6] Brewer, H. (2012). List of gender stereotypes. Health Guidance. Retrieved on May 2014, from http://www.healthguidance.org/entry/15910/1/List-of-Gender-Stereotypes.html.

[7] Burke, W. W. (2013). Organization Change: Theory and Practice: Foundations for organizational science. Thousand Oaks; Sage Publications.

[8] Chiu, C. Y., Gelfand, M., Yamagishi, T., Shteynberg, G., \& Wan, C. 2010). Intersubjective culture: The role of intersubjective perceptions in cross-cultural research. Perspectives on Psychological Science, 5, 482-493

[9] Clandinin, D. J. (2013). Engaging in narrative inquiry. Walnut Creek, CA: Left Coast Press Inc.

[10] Collins, D. B. (2002). Performance-level evaluation methods in management development from 1986 - 2000. Human Resource Development Review, 1(1), 91-110.

[11] Crane, T. (2009). Is perception a propositional attitude? The Philosophical Quarterly, 59 (236): 452-469.

[12] Crothers, L. M., Hughes, T. L., \& Morine, K. A. (2008). Theory and cases in school-based consultation, New York, NY: Routledge.

[13] Daft, R. L., (2010). Organizational theory and design. 10th ed. Mason: Cengage Learning.

[14] Daudelin, M. (1996). Learning from experience through reflection. Organizational Dynamics, 24, Winter issue 3, 36-48.

[15] Derrida, J. (2004). Living On. Deconstruction and Criticism. H. Bloom, P. D. Man, J. Derrida, G. Hartman, and J. H. Miller. London, New York, Continuum: 62-142.

[16] Ellis, S. \& Davidi, I. (2005). After event reviews: Drawing lessons from successful and Failed experience. Journal of Applied Psychology, 90, 857-71.

[17] Elmuti, D., Jai, H., \& Davis, H.H. (2009). Challenges Women Face in Leadership Positions and Organizational Effectiveness: An Investigation. Journal of Leadership Education, Vol.8, (2).

[18] Frederiksen, C. S. (2010). The relation between policies concerning corporate social responsibility (CSR) and philosophical moral theories-An empirical investigation. Journal of Business Ethics, 93 (3) 357- 371.

[19] Friedrich \& Ansell-Pearson, Keith \& Diethe, Carol. (2018). Nietzsche: On the Genealogy of Morality and Other Writings. 177-184. 10.1017/9781316562987.008.

[20] Friston, K. J., Daunizeau, J. \& Kiebel, S. J. (2009) Reinforcement learning or active inference? PLoS (Public Library of Science) One 4(7): e6421. 
[21] Foucault, M. (1980). Two Lectures. Power/Knowledge: Selected Interviews and Other Writings by Michel Foucault. C. Gordon. New York, Pantheon Books.

[22] Gibson, E. J. (1991). An odyssey in learning and perception. Cambridge, MA: MIT Press.

[23] Gibson, E. J. (1988a). Exploratory behavior in the development of perceiving, acting, and the acquiring of knowledge. Annual Review of Psychology, 39, 1-41.

[24] Gibson, E. J. (1977). How perception really develops: A view from outside the network Basic processes in reading: Perception and comprehension (pp. 155-173) Hillsdale, NJ: Erlbaum.

[25] Goleman, D. (2000). "Leadership That Gets Results.” Harvard Business Review pp. 78-90.

[26] Guglielmo, S., Monroe, A. E., \& Malle, B. F. (2009). At the heart of morality lies folk psychology. Inquiry: An Interdisciplinary Journal of Philosophy, 52, 449-466.

[27] Hannum, K. M., Martineau, J. W., \& Reinelt, C. (2007). eds. The Handbook of leadership Development Evaluation, San Francisco, CA: Jossey-Bass.

[28] Hartley, J., \& Tranfield, D. (2011). Leadership Learning in Changing Times: Evaluating leadership development in the civil service. London: Sunningdale Institute of the National School of Government.

[29] Hayes, C. (2019, April 19). Trump supporter threatens to kill Democratic lawmakers over Rep. Omar's 9/11 comments, docs say. Retrieved April 21, 2019, from https://www.yahoo.com/news/trump-supporter-threatens-kill-democratic-201723763.html.

[30] Heifetz, R. A., \& Laurie, D. L., (1997). “The Work of Leadership.” Harvard Business Review pp. 123-34.

[31] Herek, M, Gillis, G, \& Cogan, J. (2009). Internalized Stigma Among Sexual Minority Adults: Insights From a Social Psychological Perspective. Journal of Counseling Psychology, 56. 3243. 10.1037/a0014672.

[32] Hoffman, B., Mather, V., \& Fortin, J. (2017, September 24). N.F.L.: Seahawks and Titans Skip National Anthem After Trump Comments. Retrieved September 26, 2017, from https://www.nytimes.com/2017/09/24/sports/nfl-trump-anthem-protests.html?mcubz=3

[33] Jackson, D. (2011). Perception is Reality: Your Strengths Matter. Journal of Leadership Education, 10(1), 115-122.

[34] Keeney, R.L, \& Raiffa, H. (1976). Decisions with multiple objectives: Preferences and value tradeoffs. New York: John Wiley \& Sons.

[35] Jemison, V. (2018). A narrative inquiry of the perceptions leading to the under-representation of women's political leadership (Order No. 10749765). Available from Dissertations \& Theses @ University of Phoenix. (2029241547).

[36] Kassam, K.S., Koslov, K., \& Mendes, W.B. (2009). Decisions under stress: Stress profiles influence anchoring and adjustment. Psychological Science, 20 (11), 1394-1399.

[37] Kets de Vries, M. \& Korotov, K. (2007). Creating transformational executive education programmes. Academy of Management, Learning, and Education, 6 (3), 375-387.

[38] Kirkpatrick, D. L., and Kirkpatrick, J. D. (2005) Transferring Learning to Behaviour, San Francisco: Berrett-Koehler.

[39] Killen, M., Rutland, A., \& Jampol, N. (2008). Social exclusion in childhood and adolescence. In K. H. Rubin, W. Bukowski, \& B. Laursen (Eds.), Handbook of peer relationships, interactions, and groups (pp. 249 -266). New York, NY: Guilford Press. 
[40] Leckman, J.F., Panter-Brick, C. and Salah, R. (eds) (2014) Pathways to Peace: The Transformative Power of Children and Families. Strüngmann Forum Reports, vol. 15. In: J. Lupp (series ed.) Cambridge, MA: MIT Press.

[41] Lee, B. X., Donnelly, P.D., Cohen, L. et al. J Public Health Pol (2016) 37(Suppl 1): 1. https://doi.org/10.1057/s41271-016-0011-6.

[42] LeMay, N., Vollmer, N. \& Ellis, A. (2007). "Evaluating Leadership Development and Organizational Performance." In The Handbook of Leadership Development Evaluation, eds. Kelly M. Hannum, Jennifer W. Martineau, and Claire Reinelt. San Francisco, CA: Jossey-Bass, pp. 228-60. Jossey-Bass.

[43] Little P., Everitt, H., Williamson, I., (2001). Observational study of effect of patient centeredness and positive approach on outcomes of general practice consultations. British Medical Journal, 323: 408-411.

[44] Mumford, M. D., Friedrich, T. L., Caughron, J. J., \& Byrne, C. L. (2007). "Leader Cognition in Real-World Settings: How Do Leaders Think About Crises?” The Leadership Quarterly, 18 (6): 515-543.

[45] Newstrom, J. W. (1995). Review of "Evaluating training programs: The four levels of D. L. Kirkpatrick." Human Resource Development Quarterly, 6, 417-319.

[46] Northouse, P. G. (2010). Leadership: theory and practice. London: Sage.

[47] Ochsner, K.N. (2000). Are affective events richly recollected or simply familiar? The experience and process recognizing feelings past. Journal Experimental Psychology General, $129,242-261$.

[48] Phelps, E.A. (2006). Emotion and cognition: Insights from the study of the human amygdala. Annual Review of Psychology, 57, 27-53.

[49] Prevention Institute. (2011) UNITY Fact Sheet: Links between Violence and Chronic Illness. Oakland: Prevention Institute, http://www.preventioninstitute.org/component/jlibrary/ article/id-301/127.html, accessed 27 May 2016.

[50] Postmes, T., \& Smith, L. G. E. (2009). Why do the privileged resort to oppression? A look at some intragroup factors. Journal of Social Issues, 65, 769-790. doi:10.1111/j.1540-4560.2009. 01624.x.

[51] Sharot, T., Delgado, M.R., \& Phelps, E.A. (2004). How emotion enhances the feeling of remembering. Nature Neuroscience, 7, 1376-1380.

[52] Schien, E. H. (2004). Organizational culture and leadership. 3rd ed. San Francisco.

[53] Schneider, M. C. \& A. L. Bos (2014). The intersection of party and gender stereotypes In evaluating political candidates.

[54] Sonmez, F. (2019, April 14). Pelosi asks Capitol Police to step up security for Omar after Trump's 9/11 tweet. Retrieved April 16, 2019, from

https://www.washingtonpost.com/politics/pelosi-asks-capitol-police-to-step-up-security-foromar-after-trumps-911-tweet/2019/04/14/8edba93a-5ee5-11e9-bfad-

36a7eb36cb60_story.html?noredirect=on\&utm_term $=.56498 \mathrm{e} 5 \mathrm{~d} 13 \mathrm{~b} 4$.

[55] Talarico, J.M. \& Rubin, D.C. (2003). Confidence, not consistency, characterizes flashbulb memories. Psychology Science, 14, 455-461.

[56] Tosey, P., Visser, M. \& Saunders, M. N. K. (2012). The origins and conceptualizations of 'triple-loop' learning: a critical review. Management Learning, 43(3) 291-307.

[57] Veltman, A. \& Piper, M. (2014). Autonomy, Oppression, and Gender. Studies in Feminist Philosophy. Oxford University Press. 
[58] Vogel, D. L., Wade, N., \& Hackler, A. (2007). Perceived public stigma and the willingness to seek counseling: The mediating roles of self-stigma and attitudes towards counseling. Journal of Counseling Psychology. 54, 40-50.

[59] Wang, Y., (2007). On the Cognitive Processes of Human Perception with Emotions, Motivations, and Attitudes. International Journal of Cognitive Informatics and Natural Intelligence, 1(4), 1-13.

[60] Weigel, D. (2008) The Concept of Family: An Analysis of Laypeople's Views of Family Journal of Family Issues, 29:1426.

[61] Wright, D. (2017, September 24). Tom Brady calls Trump's comments 'divisive,' backs protests. Retrieved September 26, 2017, from http://www.cnn.com/2017/09/25/politics/tom-brady-nflprotests-donald-trumpnational-anthem/index.html.

[62] Yamashiro, S. K. M. (2013). Exploring heterosexist bias and oppressive bullying in antibullying prevention programs (Order No. 1548175). Available from ProQuest Dissertations \& Theses Full Text. (1466652592). Retrieved from http://search.proquest.com/docview/ 1466652592 ?accountid=35812.

[63] Yukl, G. \& Mahsud, R. (2010). Why flexible and adaptive leadership is essential. Consulting Psychology Journal: Practice and Research, 62(2), 81-93. 